\title{
Open pit mine truck robotization at the stage of rock transportation
}

\author{
Vyacheslav Zhdanov ${ }^{1}$, Andrey Kosolapov ${ }^{1}$, and Flyura Ibragimova ${ }^{2}$ \\ ${ }^{1}$ Kuzbass State Technical University named after T.F. Gorbachev, Russia, 650000, Кемерово, \\ Vesennyaya street, 28 \\ ${ }^{2}$ Kazakh Humanitarian Juridical Innovative University, Kazakhstan, Semey, Abaya street, 94
}

\begin{abstract}
The prerequisites for robotization of such a component stage of mining as mined rock transportation are considered in the article. Digitization of dump truck positioning, maneuvering and 3D map tracking forms the basis of approaching robotization. The equipment required for accident prevention in an open pit is discussed. A simplified algorithm of automated vehicle operation is offered.
\end{abstract}

\section{Introduction}

Currently, technological modernization of open pit coal mining is a key area of development for the industries of the basic complex of the Kuzbass economy (Russia's main coal cluster) [1-2]. The process of robotization and digitalization is now widespread in the mining industry [3-5]. A new challenge is the creation of unmanned equipment with high specific productivity for open cast mining.

\section{The prerequisites for mine truck robotization}

\subsection{Accident prevention when transporting mined rock}

Nowadays a lot of automobile manufacturers are staking on digitization and new services in principal counting on future where automobiles will have an ability to communicate with their operators, all their control and tracking systems will be electrified, and they will become autonomous.

It refers not only to the automobiles constructed for operation on public roads. The introduction of unmanned technologies for rock transportation amounting 30-50\% of coal mining cost will solve several system tasks in mining industry, which is on a global scale based on open pit mining. Firstly, it is cost saving; secondly, it is furthering safety of mining including potential exception of truck operator traumatizing at the stage of loading and unloading, and rock transportation as well. The gravity of any accident consequences caused by dump trucks, which total mass exceeds 500 tons, is known to be very high. Even if there are no human casualties, the expenses on evacuation and the repair of damaged machinery (Fig. 1) are very high as well. 


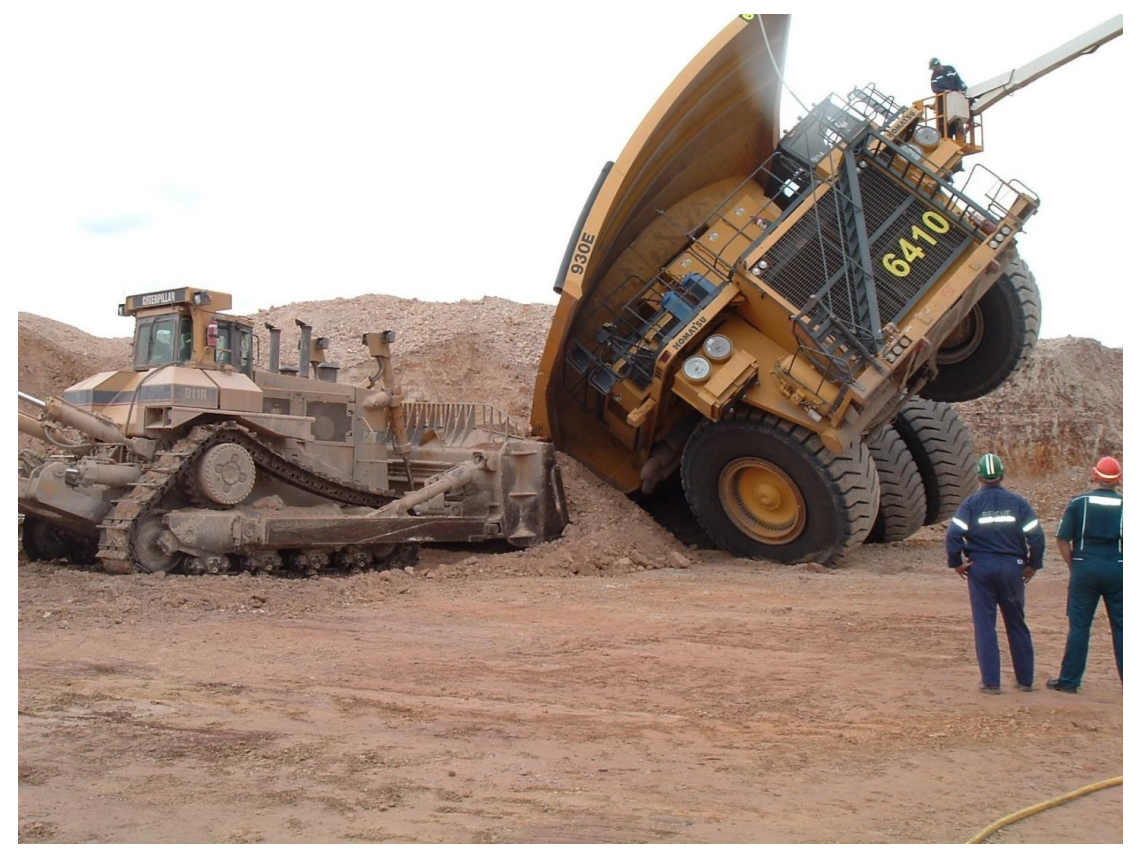

Fig. 1. A dump truck bogged down when unloading.

Thus, one of Australian companies is one of the pioneers of using unmanned dump trucks at their open pits [6]. The company continues developing technological processes to protect its employees from the harm and dangers of mining in the first place.

Similar approach is shown by Sweden company Volvo, one of the world leaders in the sphere of labor safety. The peculiarity of technological approach is the usage of a dump truck in Boliden mine, located on the north of Sweden, $100 \mathrm{~km}$ from Arvidsjaur. It is the first autonomous truck in the world [7] operating underground in the conditions of almost total darkness. The trial route is $7 \mathrm{~km}$ to the lowest point of the mine, which depth reaches 1320 m (Fig. 3).

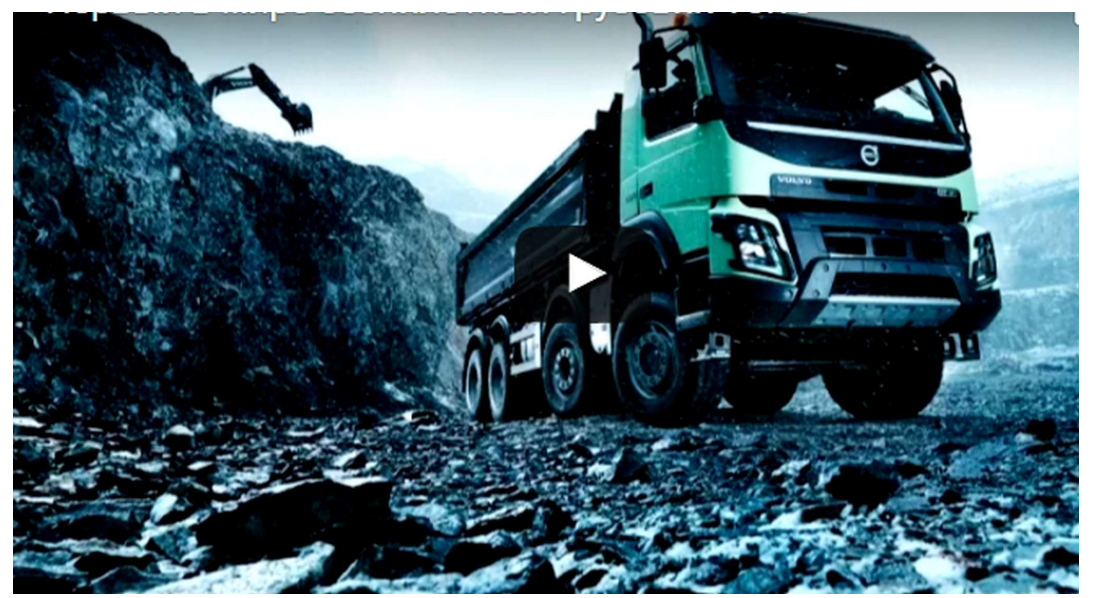

Fig. 2. Autonomous Volvo FMX used as a robot for transportation inside a mine. 
Volvo FMX dump truck operating in a mine is equipped with a set of sensors. They are used not only in this vehicle, but also in other Volvo models constructed for mass market. The sensors constantly identify the conditions of truck operation environment and prevent collisions. On-board system collects data and chooses the speed of the truck, taking into account traffic conditions and fuel saving. Volvo's attitude to unmanned driving is extremely cautious, and the unmanned truck testing in real conditions has become Volvo's first pilot project of such a level.

Similar trials are conducted by Belorussian company BelAZ.

One the one hand, a human has more experience in driving. They are creative and resourceful at avoiding accidents on a road. One the other hand, it is a human factor, which causes the vast majority of car accidents. The robot, in its turn, is capable of carrying out the actions prescribed by the algorithm precisely, and it is still to be taught to cope with nonstandard situations.

\subsection{Sensors and 3D maps}

The operation of mine trucks has some distinctive features that differ it from public traffic. Firstly, the traffic intensity is sharply different; secondly, when rock transportation, trucks execute rather simple maneuvers such as one lane traffic with no need to overtake or pass road crossing; thirdly, there are practically no unforeseen obstacles on pit roads, which are non-public technological lanes. It rather simplifies the development of traffic management algorithm.

The robot-automobile under development is to be equipped with already well-known and common in the sphere of autonomous driving sensors (a GPS device, odometers, lasers, lidars and front, rear and side cameras) to detect obstacles, which are to be avoided, and to define a traffic lane, an on-board computer for data processing and decision making, wires providing acceleration and deceleration and actuating steering to operate a vehicle and communication devices (Fig. 3) [8-10].

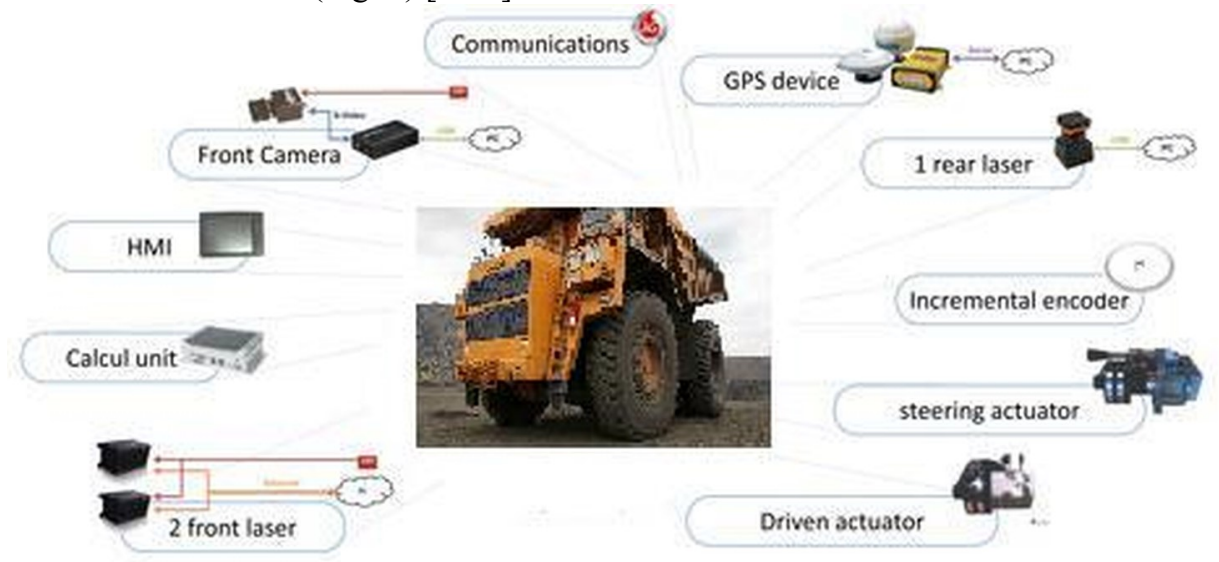

Fig. 3. Minimum equipment required for automated truck traveling.

One of essential elements for autonomous driving is a digital model of road network, which trucks operate in. The design of the model requires the whole wealth of knowledge gained in mine surveying, geodesy, cartography, and satellite positioning. The accuracy of existing systems is to be raised to a centimeter range. However, there are practically no signal suppression zones in an open pit, which is another advantage of using robots for transportation in open pit conditions. The necessity of designing the digital map of an 
operational zone, which, unlike standard maps, has to be three-dimensional, might become a significant problem.

\section{The mine truck robotization algorithm}

The assigned task to automate the management of mine truck traffic at the stage of rock transportation with the development of communication and artificial intelligence technologies, machines, and systems of unmanned engine control, transmission, deceleration and steering (by wire) will be solved by creating big data bases (big data), emergence of new professions necessary for new information flow servicing, and transportation modeling.

Mining companies will get particular benefits including financial ones as there won't be any need to deliver operators to the site, organize their feeding, recreation, and etc. Operators will move into the category of office workers working shifts while trucks will operate round-the-clock with short stops for refueling. Operators won't be in danger of having an accident, won't get tired, as it happens to drivers, or be affected by harmful burnt gases, or etc.

As a result, an optimal route will be planned according to the destination of a particular truck at present moment of time and to environment condition data. Having located itself, the robot will choose a strategy to reach the destination and the tactics of driving on the route and will control self-driving real time [10-15]. All necessary actions of truck control systems will correlate with the following simplified flowchart (Fig. 4)

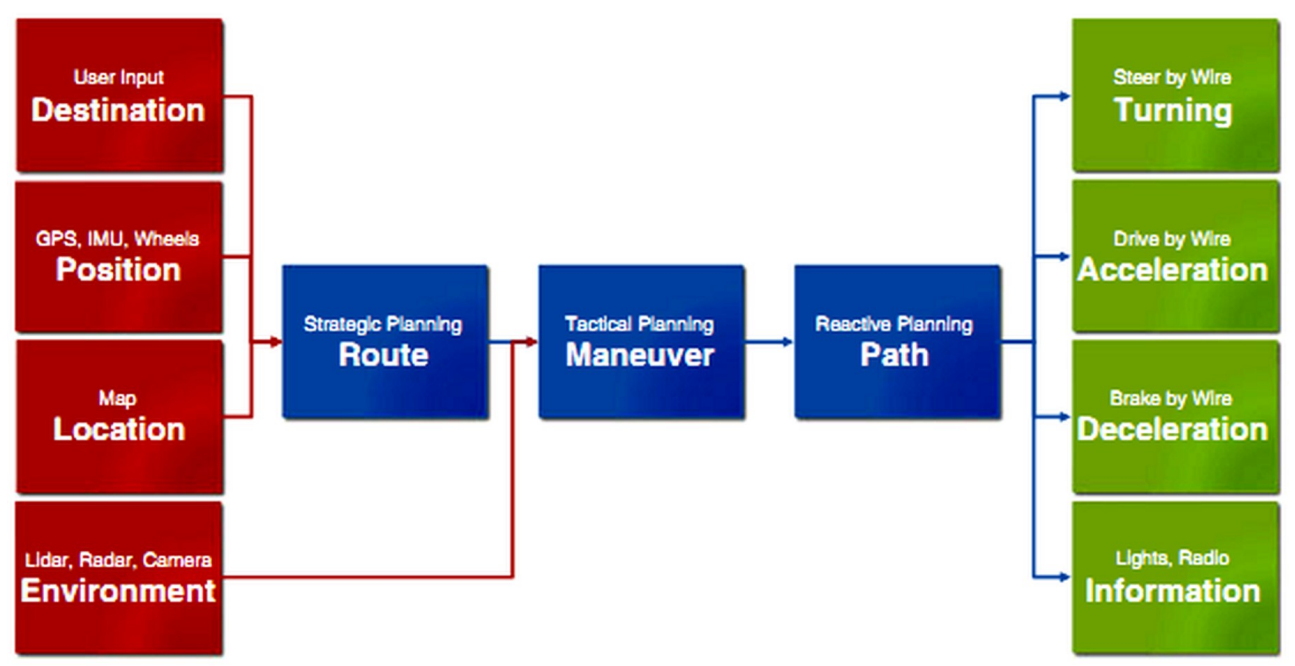

Fig. 4. The flowchart of an automated vehicle (borrowed from [10]).

\section{Conclusion}

Robotization will influence the design of dump trucks. For example, the unmanned truck won't require a driver's cabin, an I-shift and pedals, a ladder and railing or a largetonnage cabin guard which protects a driver from rocks falling from above as well. It will make the truck lighter and, thus, more efficient. 


\section{References}

1. M. Tyulenev, S. Markov, M. Cehlar, S. Zhironkin, M. Gasanov, Acta Montanistica Slovaca, 23:4, 368-377 (2018)

2. M.A. Tyulenev, S.O. Markov, M.A. Gasanov, S.A. Zhironkin, Geotech. Geol. Eng., 36:5, 2789-2797 (2018)

3. F. Abu-Abed, N. Borisov, E3S Web Conf., 21, 01019 (2018)

4. Zhironkin, O. Aleshina, V. Gorev, Y. Gunyakov, O. Zhironkina, E3S Web of Conferences, 105, 04001 (2019)

5. F. Abu-Abed, A. Khabarov, E3S Web Conf., 41, 01028 (2018)

6. Smart mining. Operating with pioneering spirit. URL: https://www.riotinto.com/ourcommitment/smart-mining-24273.aspx

7. J. Milne, Connected fleets and the smart mine (Global mining, Houston, 2017)

8. E. Pollard, F. Nashashibi, P. Resende ABV-A Low Speed Automation Project to Study the Technical Feasibility of Fully Automated Driving (ERCIM News, New York, 2013)

9. H. Li, F. Nashashibi, Robust real-time lane detection based on lane mark segment features and general a priori knowledge (IEEE ICRB, London, 2011)

10. P. Resende, Low Speed Automation: technical feasibility of the driving sharing in urban area (IEEE ITSC, Amsterdam, 2013)

11. High Definition Lidar. Velodyne corporate website. URL: http://velodynelidar.com/lidar/lidar.aspx

12. S. Beiker, Implementation of an Automated Mobility-on-Demand System, Autonomous Driving (Springer, Berlin, 2015)

13. S. Beiker, Deployment Scenarios for Vehicles with Higher-Order Automation, Autonomous Driving (Springer, Berlin, 2015)

14. Taxonomy and Definitions for Terms Related to On-Road Motor Vehicle Automated Driving Systems (SAE International, Chicago, 2014)

15. A. Kosolapov, S. Krysin, E3S Web Conf., 21, 03012 (2017) 